
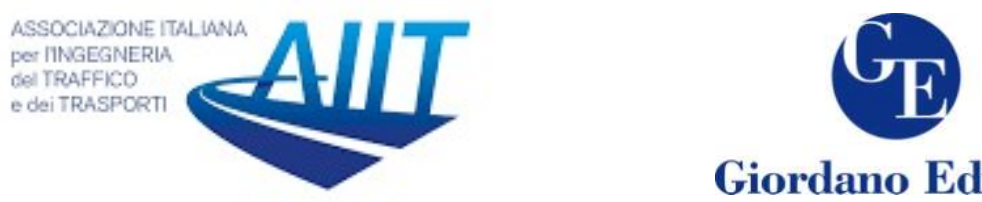

Giordano Editore

\title{
Role of COVID-19 and motionless communication on expected trends of mobility: evidence from Italian and Turin data
}

\author{
Claudia Caballini ${ }^{1}$, Bruno Dalla Chiara ${ }^{1}$, Maria Vittoria Corazza ${ }^{2 *}$, \\ Antonio Musso ${ }^{2}$ \\ ${ }^{1}$ Politecnico di Torino, Dept. DIATI - Transport systems, Turin, Italy \\ ${ }^{2}$ Sapienza University of Rome, DICEA - Department of Civil, Building and Environmental Engineering, \\ Rome, Italy
}

\begin{abstract}
The 2020-2021 pandemic has changed everyday mobility for part of the world. One of the main elements of change is the consolidation of distance working, which further prompted communications without mobility. The emergency-induced reduction of systematic travel demand has been counterbalanced by the increased volume of web traffic. As a result, communications which formerly required mobility have been regularly performed virtually during the lockdowns. This paper quantifies this phenomenon, with a focus on the Italian city of Turin, in Italy, which was one of the first countries hit by COVID-19, soon after China. Local mobility data trends before and during the lockdown are presented and compared. Implications for the "new normal" ahead are discussed. The paper provides directions for further transport policies, with the aim of advancing knowledge of this transportation topic.
\end{abstract}

Keywords: Pandemic, Travel Demand, Physical Mobility, Virtual Communication, COVID-19, Turin, Remote Activities.

\section{Introduction}

Pandemics are recurrent throughout the history of humanity, with strong impacts on people's lives, including their mobility. Once pandemics are over, people's mobility has always resumed its course after transition periods, frequently long. This is what is expected to happen after the COVID-19 health emergency. However, the current situation shows different characteristics compared to the past: on the one hand, due to the speed with which the virus has spread and, on the other hand, due to current wide availability of ICT tools and internet-based services, which enable communication between people without mobility, i.e. motionless communication, in a quick and economic way, though partial. Despite the enormous negative impacts, a positive element of this pandemic has been that it has made it possible to test the capacity and bit-rate of internet networks in a short time and at levels never achieved before.

\footnotetext{
*Corresponding author: Maria Vittoria Corazza (mariavittoria.corazza@uniroma1.it)
} 
Since the beginning of the 2000s, at least five main pandemic events can be recorded: the SARS in 2002, the H1N1 flu in 2009, the MERS and Ebola both in 2014, and the recent Chikungunya and Zika viruses in 2016. None of them, however, had the worldwide amplitude of COVID-19, nor its consequences but, in all cases, the common factor was the travel behaviours which accelerated the spread. Contemporary hypermobility made the difference (Musselwhite et al., 2020). Before the $20^{\text {th }}$ century, however, the spread of diseases was slow, according to the performances of transport modes at that time. Now they can spread rapidly through plane and high-speed train travel, as well as automobiles and public transport.

The origin of this pandemic and its expansion in China have already been extensively described (Du et al., 2020) and the circumstances facilitating the process highlighted (i.e. excellent accessibility by train and the abundance of flights associated with the New Year holidays in the outbreak city, according to Musselwhite et al., 2020). Similarly, the initial spread in northern Italy during the first half of March 2020 (Figure 1) suggests that it travelled along the highways in the most severely hit areas (Sebastiani, 2020).

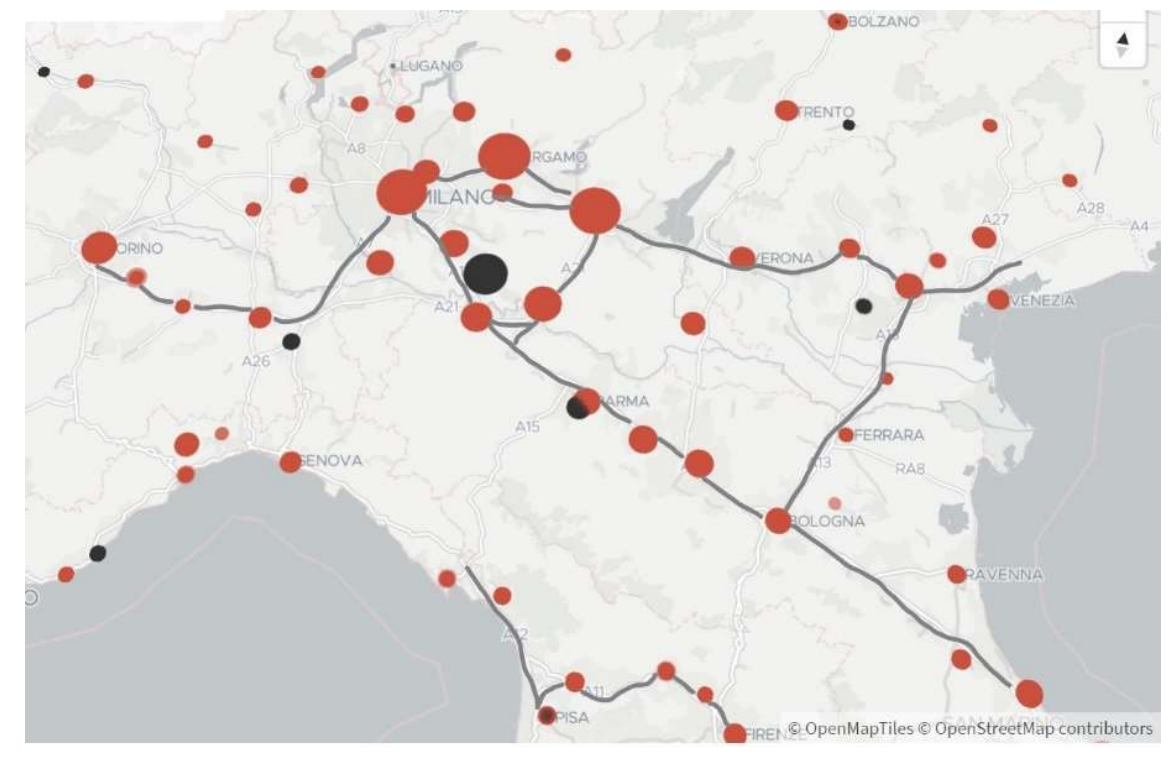

Figure 1: Relationship between COVID-19 spread and road infrastructures in Northern Italy (highways are highlighted in grey and the most affected municipalities in red)

Figure 1 introduces the problem described in this paper: the change in mobility in Italy while the pandemic was raging, leading to a total block of mobility, enforced by a severe lockdown, and the ways to achieve a new normal.

The lockdown resulted in a massive use of video conferencing, distance working, remote training, remote diagnostics, all never experienced before, with a consequent drop in the passenger travel demand. Reduced mobility was counterbalanced by motionless communication, i.e. increased virtual communication needs (Caballini et al., 2021). As a result of the COVID-19 period, remote communication may consolidate in the near future in many segments of social life. By analysing the impact of virtual communication during the COVID-19 pandemic on physical mobility in the Italian city of Turin, this paper investigates the role of virtual communications in post-pandemic world.

Turin is the capital of the region of Piedmont in north-western Italy, and is a mainly industrial and technologically oriented city of around 900,000 inhabitants. It is 
traditionally associated with the major Italian car manufacturer, and was capital of the Savoy kingdom for several centuries until 1860. Like everywhere in Italy, Turin abruptly ceased any non-basic urban function when the lockdown was enforced at the beginning of March 2020. Since Turin was one of the metropolitan areas with the highest spread rate in Italy, its study is particularly significant for studying the effects that the pandemic had on the demand for physical and virtual mobility.

\section{Physical and virtual mobility, the pre-COVID-19 trends}

Motorised mobility has nearly one century of history. The time that human beings have devoted to travelling has been largely constant over time. In the $1970 \mathrm{~s}$, the so-called travel time budget, that is, the average amount of time that people use for daily travel, seemed established. According to some studies in the literature, this budget is about an hour per day (Marchetti, 1988; Marchetti, 1994; Kellerman, 2012; Dalla Chiara et al., 2016). Some authors estimated that centuries ago, the travel time budget was also an hour a day. Although much has changed, in recent years people seem to continue to spend roughly the same amount of time on mobility, traveling more kilometres than in the past at higher speeds. This has been made possible by technological progress in the transport sector, which has allowed the development of ever faster means of transport. However, in the last few years we are witnessing a reduction in the growth of motorised mobility: Zahavi's theory (Zahavi, 1972) to explain past trends seems no longer applicable today. A crucial role in this slowing of physical mobility is due to greater attention to sustainability and to the mass use of ICT and internet-based services, which may represent an alternative to physical travel. Several studies have already analysed the relationship between ICT and physical mobility (Rodrigue, 2020; Van der Waerden et al., 2019; Konrad and Wittowsky 2018).

For about ten years, a new trend has been emerging in the transport sector: the preservation of motorised mobility in most industrialised countries. Figure 2 highlights that over the past fifteen years the number of road passenger-kilometres has slowed down, stopped or even decreased (Dalla Chiara and Pinna 2014) in several developed countries. Along with the increase and convenience of ICT technologies, other important reasons regard the conservation of the infrastructure (with the main exception of high-speed railways in some areas of the world), enforcement actions aimed at containing road accidents, high cost of fuel, restricted regulations on driving licenses, car ownership saturation, socio-demographic factors, and the scarce use of personal time while driving. Moreover, negative externalities due to the urban growth are increasingly orientating many cities towards more sustainable transport policies.

An ever wider community of people can take advantage of all forms of virtual mobility made available by technology, both in terms of services and equipment (tablets, laptops and latest generation mobile phones). This makes it possible, among other things, to work remotely, to buy from shops without having to go in person, to book travel sitting on the sofa, to manage personal relationships via e-mail and video calls, to manage bank accounts through home banking and, in some cases, interact with public administrations. The impacts of ICT on physical mobility are numerous but difficult to quantify with certainty. The major effects regard travel replacement, the possibility of carrying out activities during physical travel, the redistribution of people and freight transport (in terms of time, place, transported goods and carrier) and the generation of new mobility options (Rodrigue 2020). 


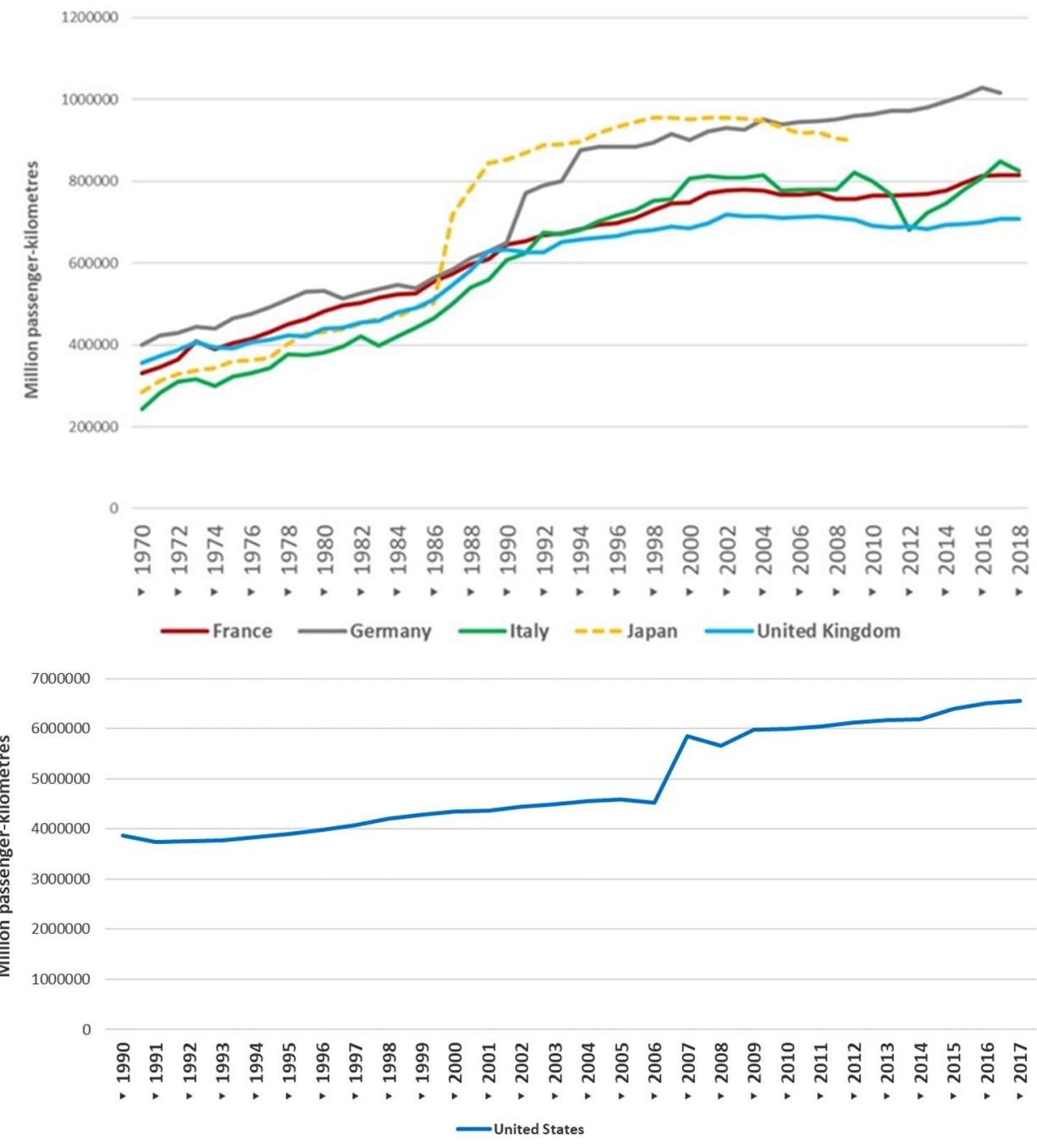

Figure 2: Passenger transport by Road in some developed Countries, $1970-2018$ (Japan until 2009).

Source: OECD 2020a.

The magnitude of fixed and wireless broadband subscriptions provides an indication of the number of connections supplied by network operators. Figure 3 plots the development of broadband subscriptions in some OECD countries per 100 inhabitants. In Italy, from 2009 to 2018 the number of fixed and wireless broadband subscriptions increased by $38,4 \%$ and $360 \%$, respectively. 

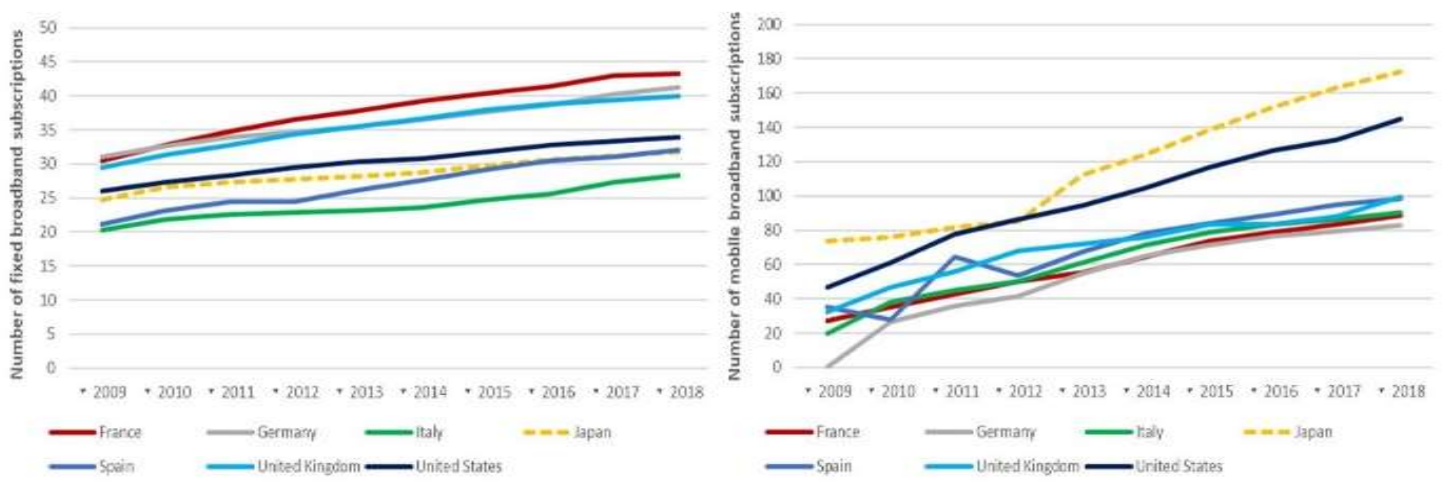

Figure 3: Fixed (left) and wireless mobile broadband (right) subscriptions per 100 inhabitants.

Source: OECD 2020b.

\section{Physical and virtual mobility trends during COVID-19 in Italy and in the city of Turin until summer 2021}

In Italy, the mobility of people during the COVID-19 health emergency underwent rapid and drastic changes, due to the progressive enforcement of lockdowns. The restrictions timeline can be reconstructed as follows:

- March, 8: initial lockdown (Phase 1) in some provinces of northern Italy (in Lombardy, Piedmont and Veneto);

- March, 11: Phase 1 further enforcement across Italy;

- $\quad$ May, 3: ending of Phase 1, at national level;

- May, 4: gradual resumption of work and commercial activities (Phase 2).

Figure 4 shows the change in trips divided by purpose, in Italy and in some Italian regions, from March 6 to April 17, 2020, taking the week of January 27-February 2 as baseline when no restrictions had been enforced. Travels associated with non-basic purposes recorded the highest decrease, especially affecting retail (partly replaced by ecommerce), leisure, access to public parks and stations. Travels to purchase essential goods (medicine or food) decreased in a milder way: 34\% in average, with peaks during the weekends. The $63 \%$ average reduction in systematic travel (i.e. to workplaces) was compensated by a massive use of remote working. The only travel type that increased (+ $32 \%$ ) was that generated by students and off-site workers to return to their places of residence. In general, travel was reduced by $80-85 \%$ by April 30, compared to the reference value (i.e., the median value related to a given day of the week, for the period of five weeks running from January 3 to February 6 2020).

Private traffic flows in the main Italian metropolitan areas began to decrease slightly from mid-January to February 20 (on average $-25 \%$, with $-40 \%$ in Milan and $-20 \%$ in Rome), probably due to citizens' concerns about the development of the pandemic. This resulted in an average $90 \%$ drop during Phase 1, with a more marked reduction in Milan, since it was close to the areas of the first outbreak, and a smaller reduction in cities such as Rome or Florence. (Figure 5). 


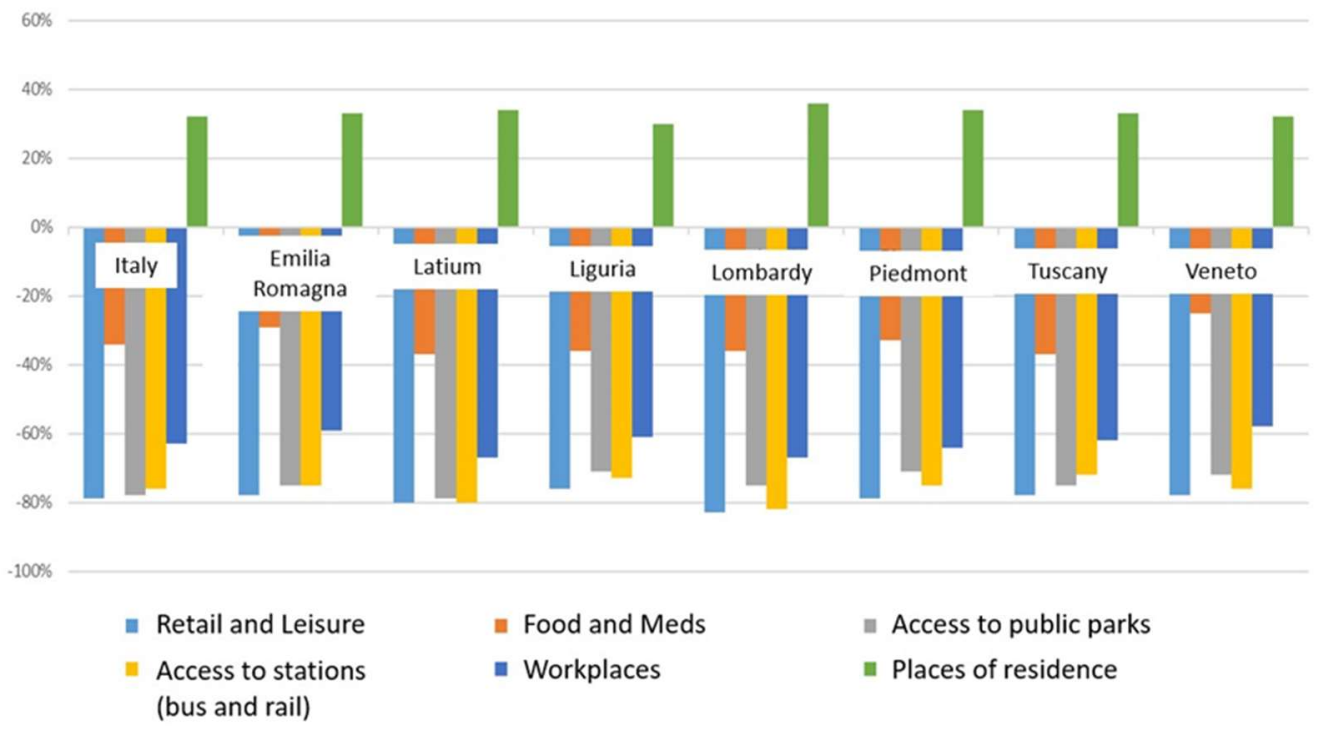

Figure 4: Variation of travels, in Italy and pandemic's most severely hit Italian Regions compared to the reference value (January 31-April 30, 2020).

Source: Google 2020.

The pandemic also influenced the modal choice: since the beginning of the lockdown, Italian citizens favoured automobiles over public transport, due to social distancing requirements and fear of contagion. In Rome, private traffic decreased by up to $78 \%$ compared to $-90 \%$ of public transport. At a national level, pedestrian mobility decreased by $75 \%$. Cycling was similarly affected. Turin is an emblematical example. The sensors installed on the main bike routes of the city recorded $67 \%$ and $73 \%$ reductions, during working days and weekends respectively, from February 23 (before the emergency) to March 29 (5T, 2020a). This can be explained by the fact that some of these bike routes connect the main university areas, which at that time were closed. Maritime and air services as well as other transport operators provided only basic services (Osservatorio Maritime Economy SRM, 2020, Hausler S. et al., 2020).

On May 3, 2020, at the beginning of Phase 2, travel was largely resumed across Italy, although public transport was far from reaching the pre-pandemic demand. Access to transit stations went from $-76 \%$ to $-45 \%$ in the period from April 17 to May 29 (Debernardi, Ferrare and Beria, 2020). Figure 6 shows the trend in the use of automobiles and pedestrian mobility in the city of Turin from January 13 to July 162020 , evidencing the rising trend in mobility. However, global mobility has not yet reached the quo ante levels: travel is increasing but on average traffic is still $-70 \%$ compared to the preCOVID-19 situation (Figure 6).

Figure 7 outlines the rapid increase in private mobility in Italy, starting in April 2021, when sanitary restrictions were gradually removed with the spread of the green passes associated to the vaccines. In Summer/Autumn 2021 Italy, which was one of the first countries hit by COVID-19 soon after China, was one of the first nations to benefit of a sharp decline in the spread of the virus and the concurrent increase in the mobility of the private transport, thanks to the highest percentages of vaccinated population in September 2021 (around 80\%). 


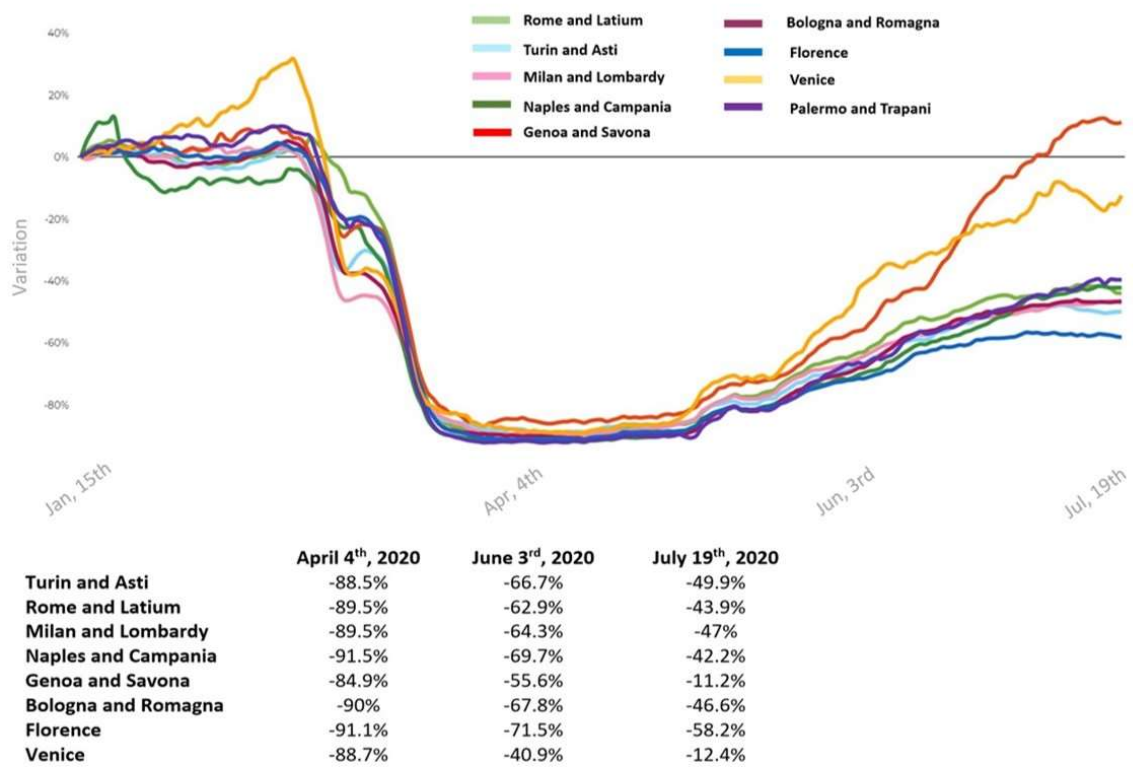

Figure 5: Decrease of passenger cars traffic flows, January 15 - April 8, 2020 in selected Italian areas.

Source: Moovit 2020.
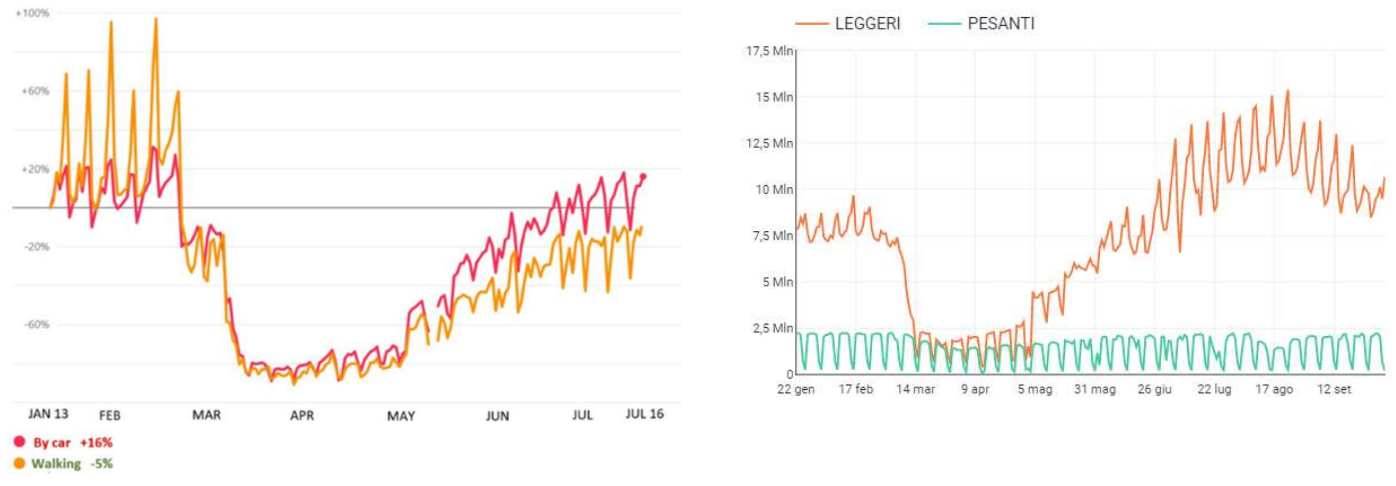

Figure 6: Trips in Turin, January 13 - July 16, 2020 (left side); trips in Italy, LDV and HDV- October 5, 2020 (right side; daily average traffic is evidently higher than preCOVID-19)

Sources: Apple 2020, Octotelematics 2020 


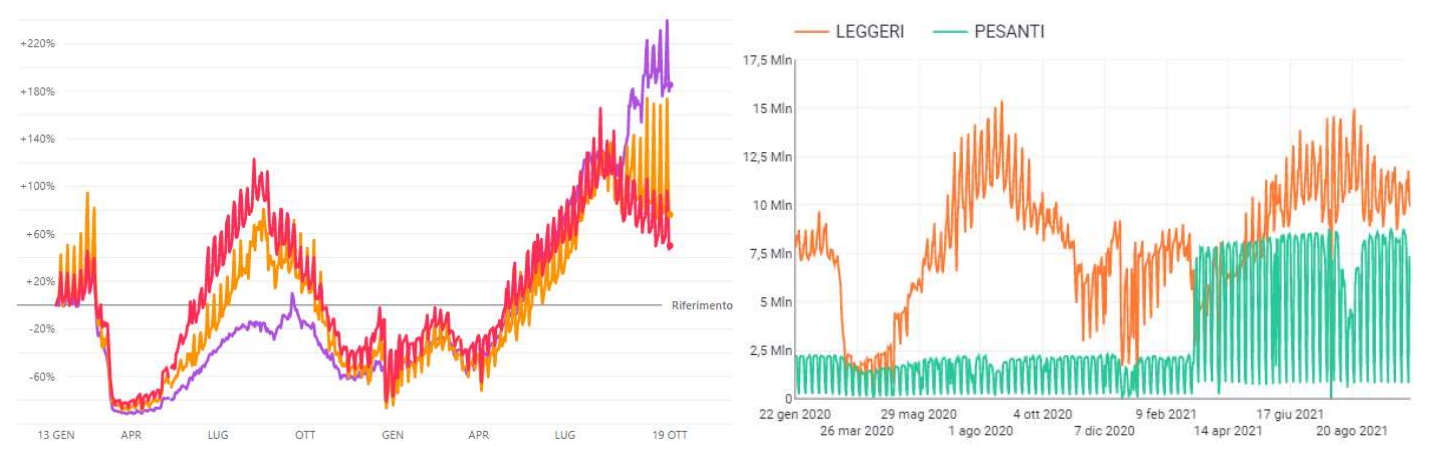

Figure 7: Trips in Italy, January 13 - October 19, 2021 (left side; by foot, yellow; by car, red; transport in purple); trips in Italy, LDV and HDV- October 16, 2021 (right side; daily average traffic is evidently higher after removal of sanitary restrictions, much oriented to private mobility)

Sources: Apple 2021, Octotelematics 2021

The data for the city of Turin, collected through inductive loop sensors, allow the description of local traffic trends. A sharp drop in mobility can be observed focusing on the first three days of Phase 2 (from Monday, May 4 to Wednesday, May 7 2020) and comparing them with the same days of the previous week (when the lockdown was still fully in place) and with those from May 2019. This occurred in terms of: average travel mileage (-5.8 km during Phase 2, which represents $-48 \%$ in May 2019); service (-84\% passengers $* \mathrm{~km}$, corresponding to 197 million against 941 million at the beginning of 2020 and 1,210 million in 2019) and traffic flows (-36\% compared to those recorded on 2019 working days), with a 50\% reduction in peak hours 2019 (7.00-9.00 a.m. and 5.007.00 p.m.). However, traffic flows compared to the previous week increased by $35 \%$, in particular $+39 \%$ in the morning peak hour and $+68 \%$ in the evening one (Figure 8 ).

Trips within the city centre, which is a restricted traffic zone, decreased by up to $60 \%$ compared to the same days in 2019 , although $+47 \%$ was recorded in comparison with the previous week. The occupancy of parking slots is no exception: in the 34 public facilities a $42 \%$ decrease compared to 2019 was observed, while practically no changes occurred $(-2 \%)$ in comparison with the previous week.

Cycling seems to be the only increasing travel option between the two analysed weeks in 2020: 18,000 records collected compared to 4,000 in the last lockdown days, corresponding to a $+335 \%$ increase on average, with $+478 \%$ in the morning peak hour and $+460 \%$ in the evening peak hour. Nevertheless, these figures are reduced by $52 \%$ if compared to 2019. However, the relevance of these data, recorded during Phase 2, is to be associated with the observation that many bike paths connect the university areas, where no activity has resumed yet. 


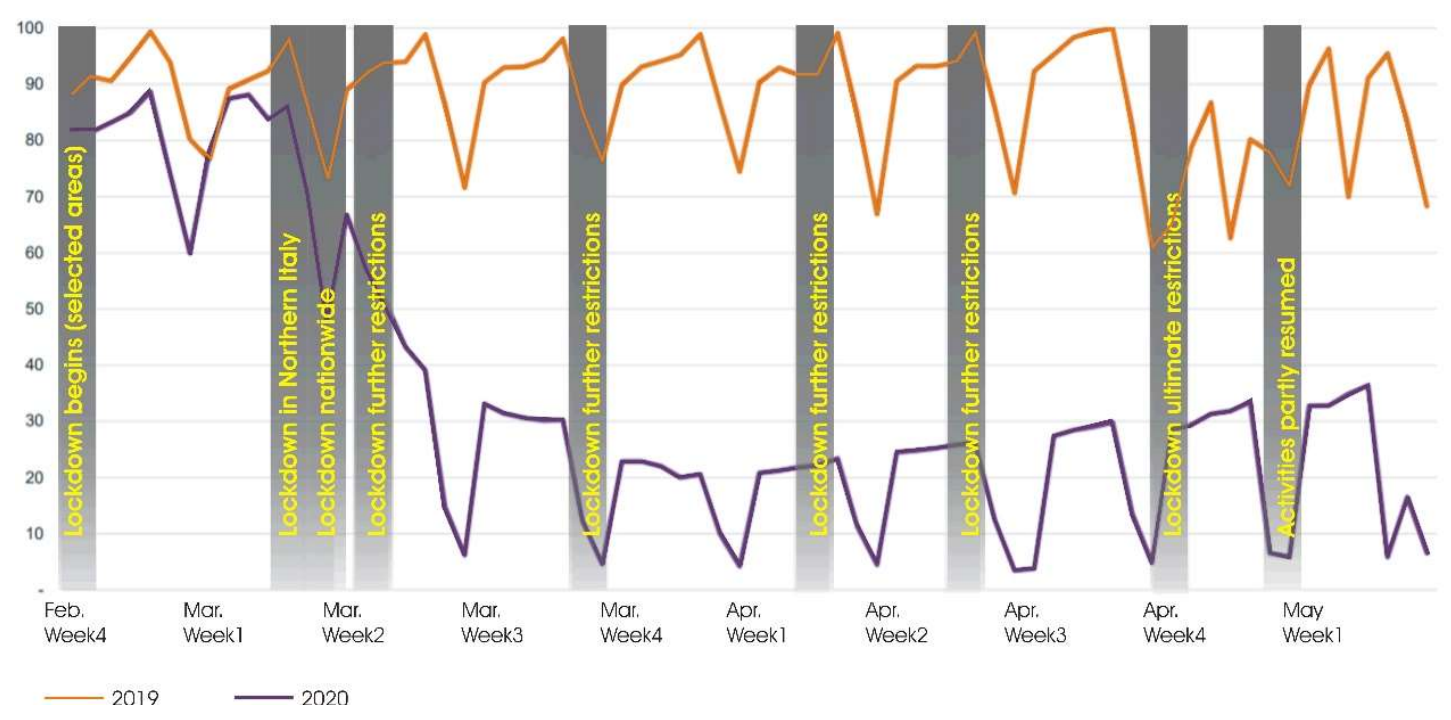

Figure 8: Car traffic in the City of Turin: comparison between 2019 and 2020. Source: 5T, 2020b.

As regards virtual mobility, since the beginning of Phase 1, the main Italian telecommunication company has recorded an overall $90 \%$ increase in volumes on the fixed network and an increase greater than $30 \%$ on the mobile network in the first quarter (March 2020-June 2020). Another major telecommunications operator showed a 35\% increase in mobile communication and a $40 \%$ increase in the fixed network in the same period.

Since the Coronavirus emergency started, in the first semester of 2020, the use of the Internet in Piedmont has grown by $20 \%$ compared to the same period in 2019 and by $50 \%$ compared to the month of January (Top-IX Consortium, 2020). The most common web search engine reached $+45 \%$, while the most extensively used social media reached $+42 \%$. During the lockdown, the most significant peak in internet traffic demand was reached and the associated increase in the use of recreational platforms evidences the attractiveness of this type of entertainment among the public at home.

\section{Future mobility scenarios after COVID-19}

The change in mobility patterns in the last decade can be seen as the combined result of motorised and virtual mobility, and the COVID-19 pandemic has highlighted even more the potential of ICT tools in morphing behaviours. It is the responsibility and prerogative of the transport engineering sector to reinvent motorised mobility in order to guarantee a new transport cycle based on conscious, efficient and safe mobility to decrease congestion phenomena, energy consumption and emissions.

Such a change in physical mobility can be guaranteed by an even greater use of ICT technologies, i.e., virtual communication, higher than pre-COVID-19 levels even if not as high as during Phase 1 of the emergency. Private motorised mobility needs to be improved by increasing the use of ITS, promoting connected vehicles and adopting greener fuels.

Assumptions of static, exogenous consumer preferences can strongly bias the market potential results for advanced environmentally-friendly technologies (Axsen, Orlebar and Skippon, 2013), especially for new concepts of connected and green vehicles, with 
assisted driving. This requires ICT, sets the basis for automated driving, and inevitably relies on interconnected vehicles. It should be recalled that the term interconnected has the original meaning of "intelligent", from the Latin inter-lego, which means "I link with or through" or "I read through", thus inferring the ability to read between the lines, in other words of being intelligent.

All this implies a very broad and long-lasting path for ITS, which in this context is conceived as interconnected and intelligent transport systems, where motionless communication is permitted on vehicles, so as to allow travellers to be connected remotely. ITS are also necessary to prevent physical mobility from being partially outranked by virtual mobility, which relies on ICT use. In this perspective, ITS can allow a common future of collaboration between transport and communications.

In some cases, this reinvention of transport systems in an ITS context has already begun: there are already road vehicles which have computerised equipment on-board and continuous vehicle monitoring, with the aim of achieving automated driving. This equipment started with the introduction of black boxes on automobiles, in Europe, a consequence of the compulsory introduction of e-calls since 2018, and integration with virtual communication, which is partially or wholly independent of oil-derived fuels.

These issues lead to another relevant point, which has been left for further research in the transport and ITS context, as it is beyond the scope of this paper. So far, vehicles have been used because their physical location is known at a given time. For instance a car parked close to one's own house or a train arriving at a station at a time that suits one's needs. ITS currently allows the knowledge of the physical position of a vehicle not only through direct experience, its ownership, or a timetable, but also through information. It is now possible to know that a sharable vehicle is available next to one's office and is free to be used. Is it therefore necessary to renounce the ownership of a vehicle, or at least at the partial usage of a private car, in favour of a shared and connected vehicle, associated with reliable information on its physical position and availability? This issue opens the market towards Mobility as a Service (MaaS), especially in urban contexts, where mobility and the number of vehicles are at the highest levels in terms of frequency and density, and travellers use public transport and car/bike sharing, rather than using their owned vehicles.

MaaS might favour a reduction in the production of private vehicles as the result of introducing a shared vehicle economy, where buyers may be large companies or public administrations. If ITS are the key to this evolution, new modern needs will be satisfied to provide more leisure time for travellers (through assisted and autonomous vehicles), to respect the environment (through green vehicles) and to provide the possibility of interacting with other people or working while traveling (through connected vehicles).

On the basis of the above, some possible answers can be drawn to the research question on the role of virtual communications in the post-COVID era:

- Virtual communications proved to be an effective resource for managing daily work activities during the pandemic. They will therefore certainly be increasingly included in the corporate culture to reduce travel costs, since the performance of remote working proved to be equal or even higher than traditional working.

- The COVID-19 experience will pave the way for further exploitations of virtual communications in other everyday activities: goods distribution, education, leisure. However, their extent and affordability without becoming detrimental to social life are unclear. 
- The fear of contagion is pushing people back to the massive use of personal automobiles. Virtual communications can help reverse this trend by making remote working into a regular option and helping to reduce commuting, with clear environmental benefits.

- Virtual communications has so far affected the wealthiest strata of society, or at least those most familiar with web literacy. To increase inclusivity, virtual communications should also include access to health care and other welfare services for those who have few travel options and are still computer-illiterate.

- Moving to reach a place is probably the travel option most affected by the COVID-19 pandemic, also thanks to the opportunity provided by virtual communications. One more reason was certainly its unpreparedness and lack of experience in managing the emergency. Until 2019, research was mainly focused on improving fleets management and control, within well-known fields as predictive maintenance, energy management, eco-driving and electrification for bus fleets (Corazza et al. 2016, Bousse et al. 2018). But the lesson learnt will likely pave the way for further innovations dictated by anticontagion measures: touchless options, more flexible on-board layouts, advanced HVAC systems, etc. The challenge for innovations in mobility is to keep the pace with current developments in all areas of virtual communications since these proved, like passenger cars, to be the main competitor in everyday mobility, and to convey the idea that transport systems are safe and suitable for all.

\section{Future mobility scenarios after COVID-19}

The confinement measures implemented during the COVID-19 emergency have lead to a structural change in the mobility of people in the post-COVID-19 period. Limiting individual mobility to a few hundred meters around home has significantly reduced the use of automobiles and of public transport, changing the usual mobility patterns. The drastic reduction of traffic, accidents and pollution in cities once again show how much human activities affect the surrounding environment.

After the emergency of Phase 1, Phase 2 exploited the COVID-19 crisis, trying to maintain the positive effects deriving from the obligation to stay at home and transforming them into resources to accelerate the path towards more sustainable urban mobility, both at an environmental and social level. Of course, economic incentives and funds are needed to meet current urgent needs (Di Giuseppe, 2020).

Mobility has been gradually recovering and a transition to the new normal is underway. The mobility demand should be managed and monitored on the basis of social distancing and other anti-contagion requirements to guarantee safe travel experiences. Failing to provide safe travel conditions will inevitably result in solo driving and a return to carbased lifestyles. This was already demonstrated by the observation of traffic in the city of Wuhan where, after the emergency, most of the commuters used the family car to return to work. This goes hand in hand with the observed decrease in public transport ridership (Park, 2020), with low ridership expected to last (Chandra, 2020). Therefore, commuting is another problem to address if the massive return to cars is to be avoided: the challenge is to provide safe travel options within quality standards.

Remote working, which during the pandemic allowed people to continue their work, can probably become an alternative or complement to previous work models thanks to some advantages (increased productivity in some contexts; reduced transport costs for workers; reduction of rent, energy and cleaning costs for companies, etc.). Remote work is likely to generate a reduction in physical mobility and an increase in connections 
between people, in turn generating a greater demand for communication. It is to be evaluated whether this new induced demand will be met with or without physical mobility. For instance, the systematic replacement of business trips with web meetings could significantly impact the demand for air and long-distance rail traffic.

How the new normal can reach satisfactory levels of sustainability is another issue to address as private cars seem to be the preferred mode in post-COVID-19. The reduction in pollution, congestion and accident rate during the pandemic cannot be considered an achievement, as the toll paid was unaffordable, and in the end the success too far to claim. Estimates showed $36 \%$ of the emissions from surface transport by the beginning of April 2020 , within a general reduction of $17 \%$ if all the emitting sources are considered. Once the lockdown has been lifted, emissions have been rising again, though their reduction is strongly addressed in many countries by policies related to new powertrains and electrification. However, if compared to the Paris COP 21 mandate, these percentages might seem modest and the efforts to generate them disproportionate: to stick to the global average temperature increase to $1.5^{\circ} \mathrm{C}$, an annual emission reduction rate of around $7.5 \%$ is required up to 2030 (Le Quéré et al., 2020).

At the same time, scientists observed that pollution may have played a possible retroactive effect on the lethality rate of the COVID-19 virus in northern Italy, one of the most polluted areas in Europe (Rugani and Caro 2020). However, the consolidation of remote working can help, in the long term, to mitigate the magnitude of accidents, congestion and its negative effects on the environment. Moreover, it, can help reducing travel stress, provided not to generate an increase in physical travel demand.

\section{Conclusions}

In the new normal, co-modality or multi-modality options boosted and MaaS promoted, paving the way for the introduction of cleaner vehicles more integrated in diversified transport supply, with a greater electrification. Therefore, a possible scenario could foresee a reduction of private mobility accompanied by a higher quality mobility supply and integrated by new paratransit options (electric kick-scooters, hover boards, seg-ways, mono-wheels, etc.). In this vision, walking and biking can become more relevant as they meet social distancing requirements and are necessary to implement MaaS services.

Transport policies are called upon to make all of the above real, but much also depends on national political commitment, necessary to convey the idea that the risk of the virus spread on public transport can be significantly reduced if individual protective equipment is regularly implemented and social distancing is respected.

The change in mobility in the last fifteen years can be seen as the combined result of motorised and virtual mobility: the COVID-19 pandemic has highlighted even more the potential of ICT tools and ITS in the ability to replace and/or modify behaviours of physical mobility.

\section{References}

5T - Tecnologie Telematiche Trasporti Traffico Torino (2020a) "Coronavirus e la mobilità ciclistica a Torino". http://www.5t.torino.it/coronavirus-mobilita-ciclisticatorino/. Accessed July 15, 2020.

5T - Tecnologie Telematiche Trasporti Traffico Torino (2020b), Reserved data received on July 12020. 
Apple (2020) "Mobility trends", https://www.apple.com/covid19/mobility. Accessed July $18,2020$.

Axsen, J., Orlebar, C., and S. Skippon (2013) "Social influence and consumer preference formation for pro-environmental technology: The case of a U.K. workplace electricvehicle study", Ecological Economics, 95, pp. 96-107.

Bousse, Y., Corazza, M.V., Sessing, G., Salzillo Arriaga D. (2018). Electrification of Public Transport in Europe: Vision and Practice from the ELIPTIC project, Proceedings of the 2018 IEEE International Conference on Environment and Electrical Engineering (EEIC), (L. Martirano, ed.), IEEE, New York, pp. 296 - 301.

Caballini, C., Agostino, M., and Dalla Chiara B. (2021). Physical mobility and virtual communication in Italy: Trends, analytical relationships and policies for the post COVID-19, Transport Policy, 110, pp. 314-334.

Chandra, S. (2020) "Speed, Space and Sustainability (3S) in Transportation Amid COVID-19 Crisis", SRN e-library, May 11, 2020. https://ssrn.com/abstract=3598501. Accessed May 30, 2020.

Corazza, M.V., Guida, U., Musso, A., Tozzi, M. (2016) "From EBSF to EBSF-2: A compelling agenda for the bus of the future: A decade of research for more attractive and sustainable buses", Proceedings of the EEEIC 2016 - International Conference on Environment and Electrical Engineering (R. Araneo, L. Martirano eds.), IEEE, New York, art. no. 7555479,

Dalla Chiara B., and I. Pinna (2014) "Sustainable transport systems: trends on needs, constraints, solutions", Science and the Future, 2, pp. 03003.

Dalla Chiara, B., Cornaglia, L., and F. Deflorio (2016) "A macro-analysis of the evolution of motorised mobility and relationships with the development of motionless communication systems", IET Intelligent Transport Systems 10 (9), pp. 613 - 621.

Debernardi. A., Ferrare, E. and P. Beria (2020). Gli impatti della pandemia sulle reti di trasporto in Italia: scenari esplorativi fase 2. TRASPOL -Research Centre on Transport Policy, Milan 2020.

Di Giuseppe F. (2020) "Come sarà la mobilità dopo il Covid-19? Riflessioni, proposte e richieste green", Ambiente ed Ambienti. https://www.ambienteambienti.com/comesara-la-mobilita-dopo-il-covid-19-riflessioni-proposte-e-richieste-green/. Accessed July 1, 2020.

Du, Z., Wang, L., Cauchemez, S., Xu, X., Wang, X., Cowling, B.J., and Meyers, L.A. (2020) "Risk for Transportation of Coronavirus Disease from Wuhan to Other Cities in China", Emerging infectious diseases 26 (5), pp. 1049-1052.

Google (2020) "Rapporti sugli spostamenti della comunità". https://www.google.com/covid19/mobility/. Accessed July 15, 2020.

Hausler S. et al. (2020) "The impact of COVID-19 on future mobility solutions", May 4, https://www.mckinsey.com/industries/automotive-and-assembly/our-insights/theimpact-of-covid-19-on-future-mobility-solutions?cid=other-eml-alt-mblmck\&hlkid=3779e50d77fc43ab84264c6c09deb1c9\&hctky=10435177\&hdpid=a5a83 544-b355-4758-8c0c-8956f09bd7f2. Accessed July 9, 2020.

Kellerman, A. (2012). Daily Spatial Mobilities, Routledge, New York 
Konrad, K., and D. Wittowsky (2018) "Virtual mobility and travel behavior of young people-Connections of two dimensions of mobility", Research in Transportation Economics 68, pp. 11-17.

Le Quéré, C., et al. (2020) "Temporary reduction in daily global CO2 emissions during the COVID-19 forced confinement", Nature Climate Change 5, pp. 1-8.

Marchetti, C. (1988) "Infrastructures for Movement: Past and Future". In: Ausubel, J.H. and Herman, R. (eds) Cities and their vital systems: infrastructure past, present, and future, The National Academies Press, Washington, D.C.

Marchetti, C. (1994) "Anthropological invariants in travel behaviour" Technological Forecasting and Social Change 47(1), pp. 5-88.

Moovit insights (2020) "Moovit Public Transit Index". https://moovitapp.com/insights/en/Moovit_Insights_Public_Transit_Index-countries. Accessed July 15, 2020.

Musselwhite, C., Avineri, E., and Susilo, Y. (2020) "The Coronavirus Disease COVID19 and implications for transport and health", Journal of Transport and Health 16, pp. 100853.

OECD. (2020a) "Passenger Transport". https://www.oecdilibrary.org/transport/passenger-transport/indicator/english_463da4d1-en. Accessed July 15, 2020.

OECD. (2020b) "Broadband subscriptions". https://data.oecd.org/broadband/fixedbroadband-subscriptions.htm\#indicator-chart. Accessed July 15, 2020.

Osservatorio Maritime Economy SRM (2020) "Osservatorio COVID-19 sui Trasporti Marittimi e la Logistica". https://www.srm-maritimeconomy.com/p/covid-19observatory-on-maritime-transport-and-logistics-april-2020/?lang=it. 2020. Accessed July 15, 2020.

Park. J. (2020) "Changes in Subway Ridership in Response to COVID-19 in Seoul, South Korea: Implications for Social Distancing”, Cureus 12(4), pp. e7668.

Rodrigue J.P. (2020). The Geography of Transport Systems. Routledge, New York

Rugani, B., and D. Caro. (2020) "Impact of COVID-19 outbreak measures of lockdown on the Italian Carbon Footprint", Science of The Total Environment, 737, pp. 13980.

Sebastiani, G. (2020). Il coronavirus ha viaggiato in autostrada? Scienzainrete. April 9th, https://www.scienzainrete.it/articolo/coronavirus-ha-viaggiato-autostrada/giovannisebastiani/2020-04-09. Accessed May 12, 2020.

Top-IX consortium (2020), "Torino Piemonte Internet Exchange". https://www.topix.org/it/. Accessed July 18, 2020.

Van der Waerden, P., Bérénos, M., and G. Wets (2019) "Communication and its relationship with digital and physical mobility patterns: a review". Advances in Transport Policy and Planning 3, pp. 3-27.

Zahavi, Y. (1972). Synthesizing a Transportation Study by the 'in' Procedure. Technodaf, Delft. 